\section{RMD Open}

Rheumatic \&

Musculoskeletal Diseases

\title{
Malignancy rates in patients with rheumatoid arthritis treated with tocilizumab
}

\author{
Andrea Rubbert-Roth, ${ }^{1}$ Anthony Sebba, ${ }^{2}$ Laura Brockwell, ${ }^{3}$ Ariella Kelman, ${ }^{4}$ \\ Benjamin Porter-Brown, ${ }^{3}$ Jennifer Pulley, ${ }^{3}$ Pavel Napalkov, ${ }^{4}$ \\ Ronald F van Vollenhoven ${ }^{5,6}$
}

To cite: Rubbert-Roth $A$, Sebba A, Brockwell L, et al. Malignancy rates in patients with rheumatoid arthritis treated with tocilizumab. RMD Open 2016;2:e000213. doi:10.1136/rmdopen-2015000213

- Prepublication history and additional material is available. To view please visit the journal (http://dx.doi.org/ 10.1136/rmdopen-2015000213).

Received 17 November 2015 Revised 14 April 2016 Accepted 19 April 2016

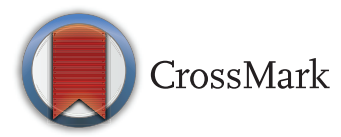

${ }^{1}$ University of Cologne, Cologne, Germany ${ }^{2}$ University of South Florida, Tampa, Florida, USA

${ }^{3}$ Roche Products Ltd., Welwyn Garden City, UK ${ }^{4}$ Genentech, South San Francisco, California, USA

${ }^{5}$ Karolinska Institute, Stockholm, Sweden ${ }^{6}$ Amsterdam Rheumatology and Immunology Center ARC Academic Medical Center, Amsterdam

Correspondence to Professor Andrea RubbertRoth; andrea.rubbert@ medizin.uni-koeln.de

\section{ABSTRACT}

Objective: To analyse malignancy rates in patients with rheumatoid arthritis (RA) treated with tocilizumab.

Methods: Patients who received tocilizumab or placebo+methotrexate/disease-modifying antirheumatic drugs in the double-blind phases of 5-phase three trials or who received at least 1 dose of tocilizumab in the long-term extension studies were analysed up to the 2 May 2012 cut-off date. Malignancies were monitored throughout the studies, analysed and adjudicated as malignant by medical review. Risk was compared with that in the general population using standardised incidence ratios (SIRs) based on data from the Surveillance Epidemiology and End Results SEER (US general population) and GLOBOCAN (nonUS general population) databases.

Results: In total, 4009 patients in the tocilizumab allexposure population were included. Mean treatment duration was 4.0 years (mean 5.1 (range 0.0-6.8); total observation time was 16120.1 patient-years (PY). The adjudicated malignancy rate $(95 \% \mathrm{Cl})$ was $1.26 / 100 \mathrm{PY}$ (1.09 to 1.44) and remained constant over time. The SIR $(95 \% \mathrm{Cl})$ for all malignancies combined, excluding non-melanoma skin cancer, was 1.36 (1.01 to 1.80 ) for US and 1.81 (1.44 to 2.23) for non-US populations, driven primarily by higher rates in lung and bronchus (US/non-US) malignancies and prostate cancer and non-Hodgkin lymphoma (non-US), in contrast to those for the general populations; these higher rates are in line with those expected in patients with RA or in the geographic regions studied.

Conclusions: Malignancy rates remained stable with long-term tocilizumab treatment, and malignancy types and rates were consistent with those expected in patients with RA.

\section{INTRODUCTION}

Patients with rheumatoid arthritis (RA) are at similar risk for most types of malignancies compared with the general population; however, they are at increased risk for certain anatomical site-specific malignancies, such as

\section{Key messages}

What is already known about this subject?

- Patients with rheumatoid arthritis (RA) are at increased risk for some types of malignancy, such as lung cancer and non-melanoma skin cancer (NMSC), compared with the general population.

- The risk for malignancy associated with immunosuppressive treatment for RA is not fully understood.

What does this study add?

- This study reports on the long-term risk for overall and site-specific malignancies in a large pool of patients with RA treated with the antiinterleukin-6 receptor- $\alpha$ antibody tocilizumab in phase 3 clinical trials and long-term extensions.

How might this impact on clinical practice?

- Overall and site-specific (including lung cancer and NMSC) malignancy rates remained stable with long-term tocilizumab treatment over a mean of 4 years and were consistent with rates expected in patients with RA.

- Clinicians should continue to monitor for malignancies in patients treated with tocilizumab to provide longer term risk assessment.

lymphoma and lung cancer, and may even be at increased risk for skin cancer, particularly non-melanoma skin cancer (NMSC). ${ }^{1-6}$ Large epidemiological studies show that risk for lung malignancy is estimated to be 20 $80 \%$ higher, ${ }^{1} 78$ risk for lymphoma is approximately twice as high ${ }^{79} 10$ and risk for NMSC is $60-90 \%$ higher in patients with $\mathrm{RA}^{38}$ compared with the general population.

The risk for malignancy, including haematological malignancy, is potentially greater in patients with RA who use immunosuppressive agents. ${ }^{11} 12$ Case reports describe lymphoma in patients with RA treated with 
methotrexate (MTX). ${ }^{13}$ The current hypothesis is that RA itself or, more specifically, the inflammatory activity associated with the disease drives the increased lymphoma risk. ${ }^{14}$ Additionally, some evidence suggests that patients with RA treated with biologics are at increased risk for malignancy, specifically NMSC, compared with the general population. ${ }^{1}$ Some studies have shown an increased risk for overall malignancies (including lymphoma, leukaemia, NMSC and lung cancer) with antitumour necrosis factor (aTNF) treatment. ${ }^{6}{ }^{15-18}$ Other observational and clinical trial data failed to demonstrate an increased risk. ${ }^{2} 791017$ 19-23 Clear differences in malignancy rates have not been reported between other RA treatment and control groups (placebo or disease-modifying antirheumatic drugs (DMARDs)) during the relatively short placebo-controlled periods of randomised trials to date. ${ }^{20}$

Systemic inflammation in RA is associated with increased risk for malignancy. ${ }^{24}$ Interleukin-6 (IL-6) is an inflammatory cytokine involved in local and systemic manifestations of $\mathrm{RA}^{25}$ and is implicated in the growth and transformation of multiple myeloma and ovarian, lung, bladder, breast, colon and prostate cancers. ${ }^{26}$ IL-6 transgenic mice develop transplantable monoclonal plasmacytomas, akin to multiple myeloma in humans, 2527 and IL-6 is involved in the growth of human myeloma and human renal carcinoma cells in vitro. ${ }^{28} 29$

Tocilizumab is a humanised monoclonal antibody that binds to membrane-bound and soluble IL-6 receptor- $\alpha,{ }^{30}$ thereby inhibiting IL-6-mediated proinflammatory signalling. ${ }^{31}$ The efficacy and safety of tocilizumab in combination with DMARDs and as monotherapy have been demonstrated in phases 3 and 4 randomised controlled trials. ${ }^{32-37}$ Malignancies were observed in active and control arms of the double-blind, placebo-controlled periods. The overall rate of malignancy remained stable with continued exposure to tocilizumab during long-term extensions of phase 3 trials. $^{38}$ Here, we present data on malignancies in patients with RA exposed to tocilizumab in phase 3 trials and longterm extension studies. Rates were compared with those in the general population using standardised incidence ratios (SIRs) based on data from regional cancer registries.

\section{METHODS}

\section{Patients}

Patients were included from the five core phase 3 placebo-controlled studies ${ }^{32-36}$ and long-term extension studies. In the phase 3 studies, patients were randomly assigned to receive intravenous tocilizumab $8 \mathrm{mg} / \mathrm{kg}$ \pm MTX/DMARD, intravenous tocilizumab $4 \mathrm{mg} / \mathrm{kg}$ + MTX/DMARD or placebo+MTX/DMARD every 4 weeks. In the long-term extension studies, patients received open-label tocilizumab 4 or $8 \mathrm{mg} / \mathrm{kg}$ every 4 weeks, alone or in combination with MTX/DMARD. Patients who received a single dose of tocilizumab
$10 \mathrm{mg} / \mathrm{kg}$ in a clinical pharmacology study (and had the option to enrol in a long-term extension) were also included.

For the current analysis, data were assessed in two patient populations. The pooled placebo-controlled population included placebo-controlled data from the double-blind phases of the phase 3 studies; these patients have been described. ${ }^{38}$ Data were included from randomisation until the first treatment change (escaping to rescue therapy with tocilizumab or entering the extension studies or reaching 1 year duration in the radiographic study in DMARD-inadequate responder (IR) patients) and are presented by randomised treatment group. The tocilizumab all-exposure population included pooled data from all patients who received at least one dose of tocilizumab in the phase 3 trials, the clinical pharmacology study and the long-term extension studies. Data were included from the first dose of tocilizumab (defined as baseline) until the clinical cut-off date of 2 May 2012. Data were analysed overall and by DMARD-IR and aTNF-IR patient populations.

\section{Assessments}

The total patient-years (PY) of exposure (duration in the study) to tocilizumab was calculated in the pooled placebo-controlled population as the last safety observation date minus the first study drug dose date +1 (escape therapy excluded). Exposure was calculated in the tocilizumab all-exposure population as the last safety observation date minus the first tocilizumab dose date +1 .

Routine safety monitoring for potential malignancy occurred throughout the studies. In addition, investigators were queried by targeted questionnaire to ascertain details such as tissue diagnosis and biopsy results. Adverse events (AEs) were coded using the Medical Dictionary for Regulatory Activities (MedDRA), V.15.0. Malignancies were identified using a validated predetermined set of terms contained in the Malignant or Unspecified Tumors Standardized MedDRA Queries (SMQ) Narrow (see online supplementary table S1).

Rates of malignancy AEs (including serious and nonserious events) were calculated overall and by 6 -month periods as the total number of AEs divided by the total PY of exposure and were expressed per 100 PY with 95\% CIs. Multiple occurrences of AEs were counted. Overall malignancy rates were based on all reported events retrieved by the MedDRA SMQ. Adjudicated malignancy rates were based on events identified by the MedDRA SMQ which were adjudicated as malignant after medical review of an event's details by physicians employed by the study sponsor. Medical review was performed to identify malignant lesions and to ensure terms were consistent with malignancy, irrespective of histological confirmation. Events adjudicated as malignancies, and those in which malignancy was not confirmed but could not be excluded, were considered malignant for the analysis. Events not adjudicated as malignant included confirmed benign tumours, in situ 
neoplasms of the cervix uteri, Bowen's disease and lesions likely to be benign (such as stable pulmonary lesions that did not require further follow-up by the treating physician).

To determine whether the number of malignancies observed with tocilizumab was greater or less than that expected in a general population, SIRs (ratios of observed to expected malignancies) were calculated. Age-specific and sex-specific malignancy rates in the general populations based on the US Surveillance Epidemiology and End Results (SEER) for the US National Cancer Institute (years 2000-2008) and the International Agency for Research on Cancer GLOBOCAN database (year 2012) ${ }^{39}$ were used to calculate the expected number of site-specific malignancies for US and non-US patients, respectively, in the tocilizumab all-exposure population. The $95 \%$ CI for each SIR was calculated to determine whether the observed number of malignancies in the tocilizumab all-exposure population was significantly different from the expected number. All SIRs having 95\% CIs excluding 1.00 were considered statistically significant. SIRs were calculated for overall malignancy and for specific anatomical sites. For calculation of the SIR only, NMSC cases were excluded because these events are not collected in the SEER and GLOBOCAN databases.

\section{RESULTS}

\section{Patient populations}

The pooled placebo-controlled population included 4098 patients (2644 treated with tocilizumab \pm MTX/ DMARD and 1454 treated with placebo+MTX/ DMARDs, providing 1560.3 PY duration for tocilizumabtreated patients and 742.7 PY duration for placebo + MTX/DMARD-treated patients). Baseline demographics and disease characteristics in the pooled placebocontrolled population were well balanced between the placebo and the tocilizumab arms (table 1). ${ }^{32-36}$

In total, 4009 patients provided data in the tocilizumab all-exposure population. The mean (SD) duration of exposure to tocilizumab was 4.0 (1.92) years (median (range), 5.1 (0.0-6.8) years). The overall total observation time was 16120.1 PY (DMARD-IR patients, 11815.1 PY; aTNF-IR patients, 1629.8 PY). Baseline RA characteristics were representative of moderate-to-severe disease (table 1).

\section{Overall malignancies}

In the pooled placebo-controlled population, the overall rate of malignancies or unspecified tumours, including NMSC, was $1.60 / 100$ PY (95\% CI 1.04 to 2.37) for tocilizumab-treated patients and 1.48/100 PY (95\% CI 0.74 to 2.65) for placebo+MTX/DMARD-treated patients. No evidence of differences in pattern or type of malignancy was reported between groups. Adjudicated malignancy rates, including and excluding NMSC in tocilizumab-treated patients (1.09/100 PY
(95\% CI 0.63 to 1.74$)$ and $0.71 / 100$ PY (95\% CI 0.35 to 1.26)), were no greater than those observed in placebo +MTX/DMARD-treated patients (1.35/100 PY (95\% CI 0.65 to 2.48 ) and $0.94 / 100$ PY (95\% CI 0.38 to 1.94$)$ ).

In the tocilizumab all-exposure population, the overall rate of malignancies and unspecified tumours, including NMSC, was 1.54/100 PY (95\% CI 1.35 to 1.74 ) based on 248 events in 220 patients. The rate excluding NMSC was $1.12 / 100 \mathrm{PY}$ (95\% CI 0.96 to 1.29 ).

On medical review, of the 248 reported events, 129 were adjudicated as malignant, 68 were adjudicated as NMSC and 6 could not be excluded as malignant because of insufficient information, for a total of 203 adjudicated malignancies. Forty-five events were adjudicated not to be malignancies: 8 were benign, 3 were metastases reported in addition to the primary tumour (the primary tumour was separately analysed) and 34 were in situ neoplasm of cervix uteri, Bowen's disease or lesions likely to be benign.

The adjudicated malignancy rate, including NMSC, for the tocilizumab all-exposure population was 1.26/ $100 \mathrm{PY}$ (95\% CI 1.09 to 1.44 ), and the rate remained consistent over time (figure 1A). The rate for DMARD-IR patients was $1.18 / 100$ PY (95\% CI 0.99 to 1.39 ), and the rate for aTNF-IR patients was 2.09/100 PY (95\% CI 1.44 to 2.92). The adjudicated malignancy rate, excluding NMSC, for the tocilizumab all-exposure population was $0.84 / 100$ PY (95\% CI 0.70 to 0.99 ) based on 135 events. The rate for DMARD-IR patients was 0.81/ 100 PY (95\% CI 0.66 to 0.99 ) based on 96 events, and the rate for aTNF-IR patients was $1.35 / 100 \mathrm{PY}(95 \%$ CI 0.85 to 2.04 ) based on 22 events. This rate also remained consistent over time (figure 1B). The most commonly reported malignancy events were NMSC, including 42 basal cell carcinomas and 26 squamous cell carcinomas of the skin. The rate of NMSC for the tocilizumab all-exposure population was $0.42 / 100$ PY $(95 \%$ CI 0.33 to 0.53 ) based on 68 events. The rate for DMARD-IR patients was $0.36 / 100 \mathrm{PY}$ (95\% CI 0.26 to 0.49 ) based on 43 events, and the rate for aTNF-IR patients was 0.74 (95\% CI 0.38 to 1.29 ) based on 12 events.

\section{Standardised incidence ratios}

Based on 135 adjudicated malignancies, excluding NMSC, in the tocilizumab all-exposure population, sexstratified, age-standardised SIRs were calculated for overall malignancy and anatomical site-specific malignancy using the SEER and GLOBOCAN databases as references for malignancy rates in the general US and general non-US patient populations, respectively. SIRs for all patients (US and non-US combined) are shown in online supplementary table S2. SIRs for overall malignancy (malignancies at all sites) were 1.36 (95\% CI 1.01 to 1.80 ) and 1.81 (95\% CI 1.44 to 2.23 ) for US and non-US patients, respectively, indicating that the observed number of overall malignancies in tocilizumabtreated patients was higher than that in the overall general population based on age-specific and sex- 


\begin{tabular}{|c|c|c|c|c|c|}
\hline & \multicolumn{2}{|c|}{ Pooled placebo-controlled population } & \multicolumn{3}{|c|}{ TCZ all-exposure population } \\
\hline & $\begin{array}{l}\mathrm{TCZ} \pm M T X / D M A R D \\
\mathrm{n}=2644\end{array}$ & $\begin{array}{l}\text { Placebo+MTX/DMARDs } \\
n=1454\end{array}$ & $\begin{array}{l}\text { Total } \\
\mathrm{N}=4009\end{array}$ & $\begin{array}{l}\text { DMARD-IR } \\
\mathrm{n}=2904\end{array}$ & $\begin{array}{l}\text { aTNF-IR } \\
\mathrm{n}=464\end{array}$ \\
\hline Female, n (\%) & $2179(82)$ & $1184(81)$ & $3286(82)$ & $2398(83)$ & $373(80)$ \\
\hline Age, years & $52.2(12.50)$ & $51.8(12.83)$ & $52.0(12.54)$ & $52.2(12.39)$ & $52.6(12.73)$ \\
\hline \multicolumn{6}{|l|}{ Race, n (\%) } \\
\hline White & $1952(74)$ & $1082(74)$ & $2970(74)$ & $2075(71)$ & $421(91)$ \\
\hline Asian & $202(8)$ & $112(8)$ & $304(8)$ & $247(9)$ & $11(2)$ \\
\hline \multicolumn{6}{|l|}{ American } \\
\hline Indian/Alaska & $190(7)$ & $95(7)$ & $274(7)$ & $218(8)$ & $5(1)$ \\
\hline \multicolumn{6}{|l|}{ Native } \\
\hline Black & $113(4)$ & $60(4)$ & $176(4)$ & $124(4)$ & $20(4)$ \\
\hline Other & $187(7)$ & $105(7)$ & $285(7)$ & $240(8)$ & $7(2)$ \\
\hline Duration of RA, years & $9.2(8.41)$ & $8.7(8.47)$ & $9.3(8.51)$ & $9.4(8.33)$ & $11.9(9.10)$ \\
\hline DAS28 & $6.7(0.98)$ & $6.7(0.96)$ & $6.4(1.28)$ & $6.4(1.23)$ & $6.7(1.12)$ \\
\hline Oral corticosteroid use, $\mathrm{n}(\%)$ & NA & NA & $2318(58)$ & $1746(60)$ & $(275(59)$ \\
\hline$\geq 1$ background DMARD, $n(\%)$ & NA & NA & $3456(86)$ & $2887(99)$ & $464(100)$ \\
\hline $\mathrm{CRP}, \mathrm{mg} / \mathrm{dL}$ & $2.6(3.03)$ & $2.7(3.64)$ & $2.4(2.90)$ & $2.3(2.73)$ & $3.1(3.59)$ \\
\hline $\mathrm{ESR}, \mathrm{mm} / \mathrm{h}$ & $48.3(26.75)$ & $49.1(27.23)$ & $46.1(26.83)$ & $46.1(26.44)$ & $50.2(28.24)$ \\
\hline Tender joint count & $30.4(15.36)$ & $29.9(15.13)$ & $28.0(16.60)$ & $27.8(16.41)$ & $31.0(16.57)$ \\
\hline Swollen joint count & $18.8(10.8)$ & $18.5(10.61)$ & $17.3(11.51)$ & $17.3(11.32)$ & $18.7(11.42)$ \\
\hline $\begin{array}{l}\text { All data are mean (SD) unless stated } \\
\text { aTNF-IR, antitumour necrosis factor-in } \\
\text { DMARD-IR, disease-modifying antirhe } \\
\text { tocilizumab. }\end{array}$ & $\begin{array}{l}\text { sponders; CRP, C reac } \\
\text { inadequate responders }\end{array}$ & $\begin{array}{l}\text { DAS28, Disease Activity Sc } \\
\text { hrocyte sedimentation rate; }\end{array}$ & $\begin{array}{l}28 \text { joints; DM } \\
\text { exate; NA, not }\end{array}$ & A, rheumatoid & $\begin{array}{l}\text { drug; } \\
\text { Z, }\end{array}$ \\
\hline
\end{tabular}


Figure 1 Adjudicated

malignancy rates including NMSC

(A) and excluding NMSC (B) over time in the tocilizumab

all-exposure population. Data are presented as rates/100 PY, and error bars are $95 \%$ Cls. $n=$ total number of adverse events; multiple occurrences of the same adverse event in one patient are counted as individual events.

aTNF-IR, antitumour necrosis factor-inadequate responders; DMARD-IR, disease-modifying antirheumatic drug-inadequate responders; PY, patient-years.

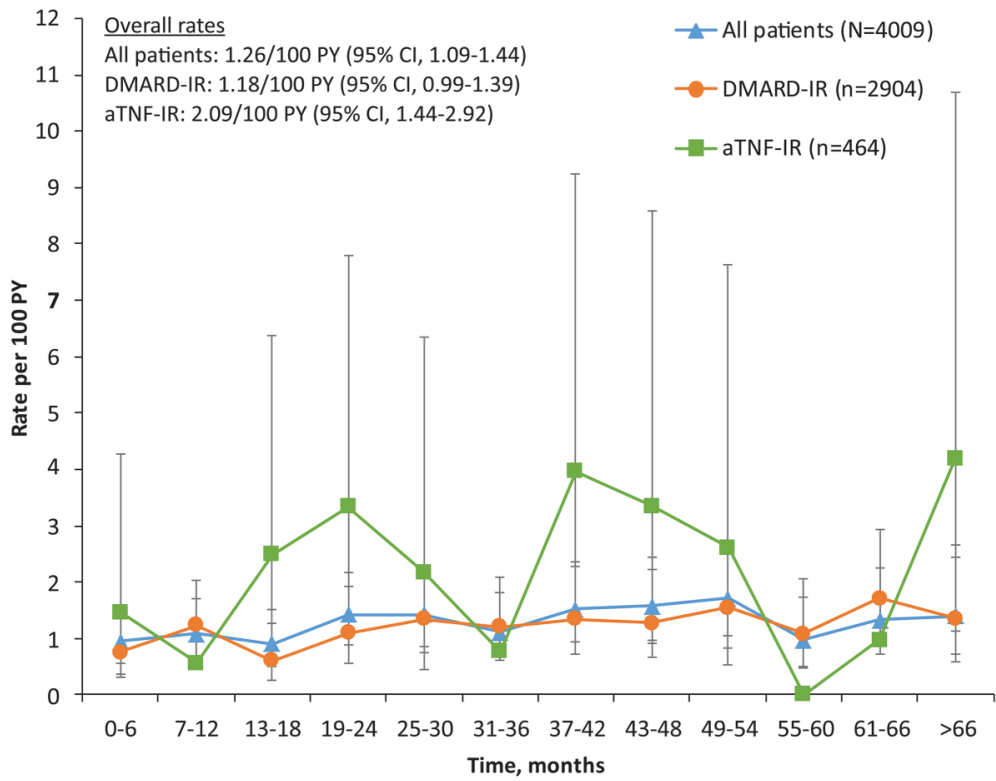

All patients

$\begin{array}{lllllllllllll}\text { Exposure, PY } & 1805.4 & 1665.7 & 1551.5 & 1476.7 & 1410.1 & 1355.8 & 1315.7 & 1268.9 & 1226.1 & 1139.4 & 1049.0 & 855.7\end{array}$

DMARD-IR

$\begin{array}{lllllllllllll}\text { Exposure, PY } & 1313.1 & 1221.6 & 1142.8 & 1088.3 & 1041.2 & 1001.9 & 973.3 & 940.3 & 907.4 & 834.8 & 759.4 & 591.1\end{array}$

aTNF-IR

$\begin{array}{lllllllllllll}\text { Exposure, PY } & 205.1 & 179.6 & 160.5 & 149.6 & 138.2 & 130.3 & 126.2 & 119.3 & 114.9 & 107.7 & 102.6 & 95.7\end{array}$

B

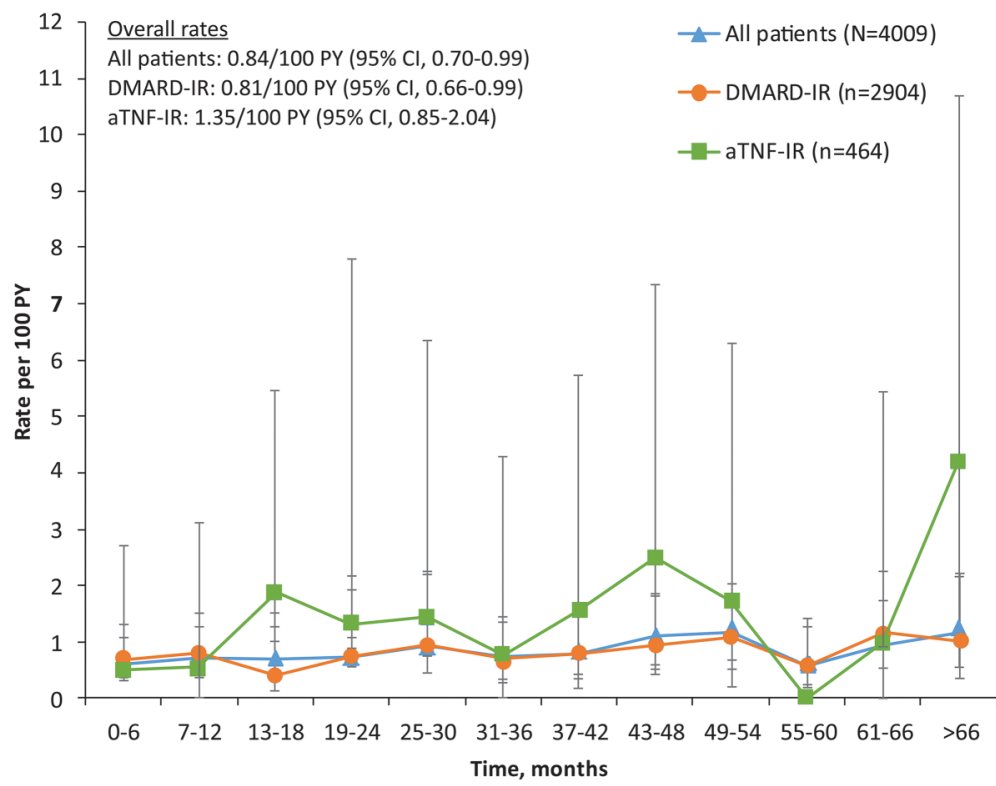

All patients

$\begin{array}{lllllllllllll}\text { Exposure, PY } & 1805.4 & 1665.7 & 1551.5 & 1476.7 & 1410.1 & 1355.8 & 1315.7 & 1268.9 & 1226.1 & 1139.4 & 1049.0 & 855.7\end{array}$

DMARD-IR

$\begin{array}{lllllllllllll}\text { Exposure, } \mathrm{PY} & 1313.1 & 1221.6 & 1142.8 & 1088.3 & 1041.2 & 1001.9 & 973.3 & 940.3 & 907.4 & 834.8 & 759.4 & 591.1\end{array}$

$n$

aTNF-IR

$\begin{array}{lllllllllllll}\text { Exposure, PY } & 205.1 & 179.6 & 160.5 & 149.6 & 138.2 & 130.3 & 126.2 & 119.3 & 114.9 & 107.7 & 102.6 & 95.7\end{array}$ 
specific rates in their respective reference populations (figure 2A, B). The increase was driven by increased SIRs in a few specific anatomical sites. In the USA, the increase was observed for lung and bronchus malignancies only (SIR 3.17 (95\% CI 1.77 to 5.23)). For all other malignancy types, the number observed in the tocilizumab all-exposure population was not significantly different from the expected number of malignancies based on rates in the reference US general population. Patients outside the USA also had a higher incidence of lung and bronchus cancer compared with the general population using the GLOBOCAN database (SIR 2.41 (95\% CI 1.32 to 4.05$)$ ). The numbers of adjudicated prostate malignancies (SIR 4.68 (95\% CI 2.01 to 9.21)) and non-Hodgkin lymphoma (SIR 3.98 (95\% CI 1.07 to 10.18)) were also higher among tocilizumab-treated, non-US patients than among the general population (figure 2B).

Lung and bronchus malignancies were the most commonly reported in tocilizumab-treated patients; 29 adjudicated cases were reported. Of these 29 cases, 24 occurred in patients who were current smokers or who had a history of smoking, 20 occurred in patients 60 years of age or older ( 2 were in patients younger than 50 years) and 4 were reported as small cell lung cancer. These findings are consistent with previous data showing

A

USA

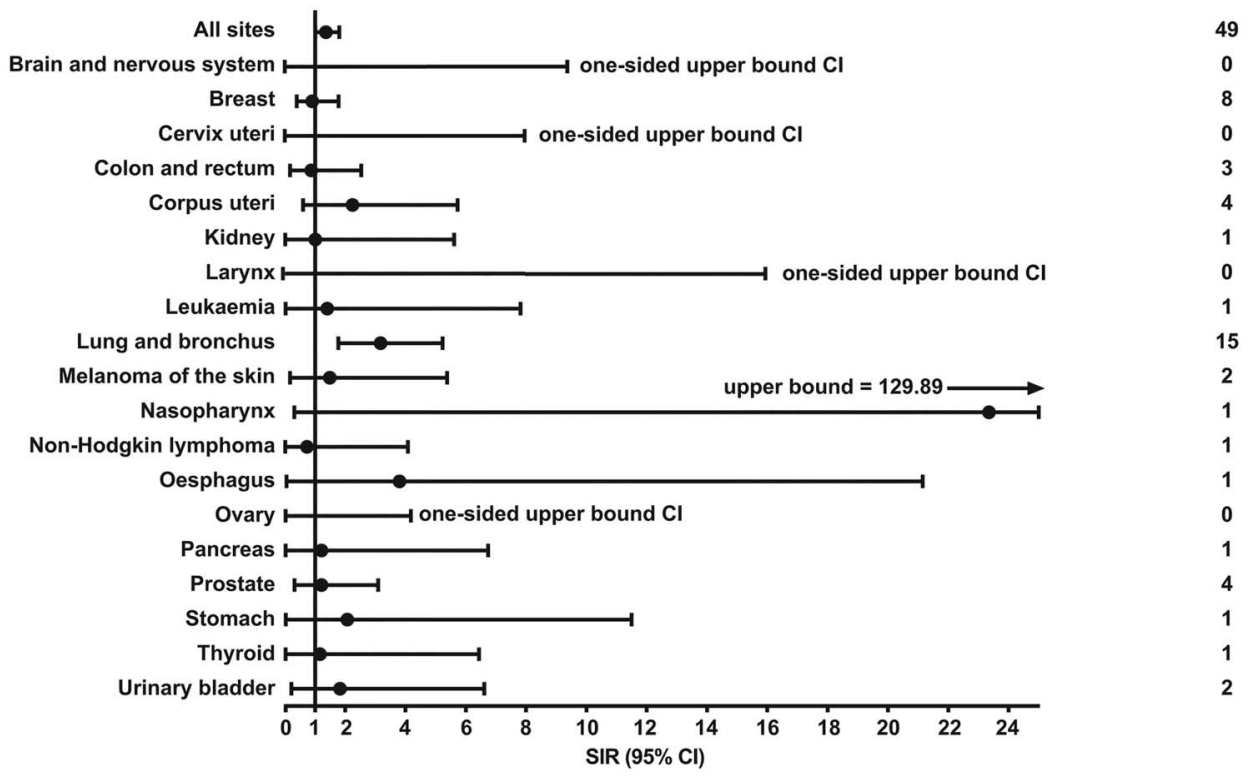

B

Non-USA

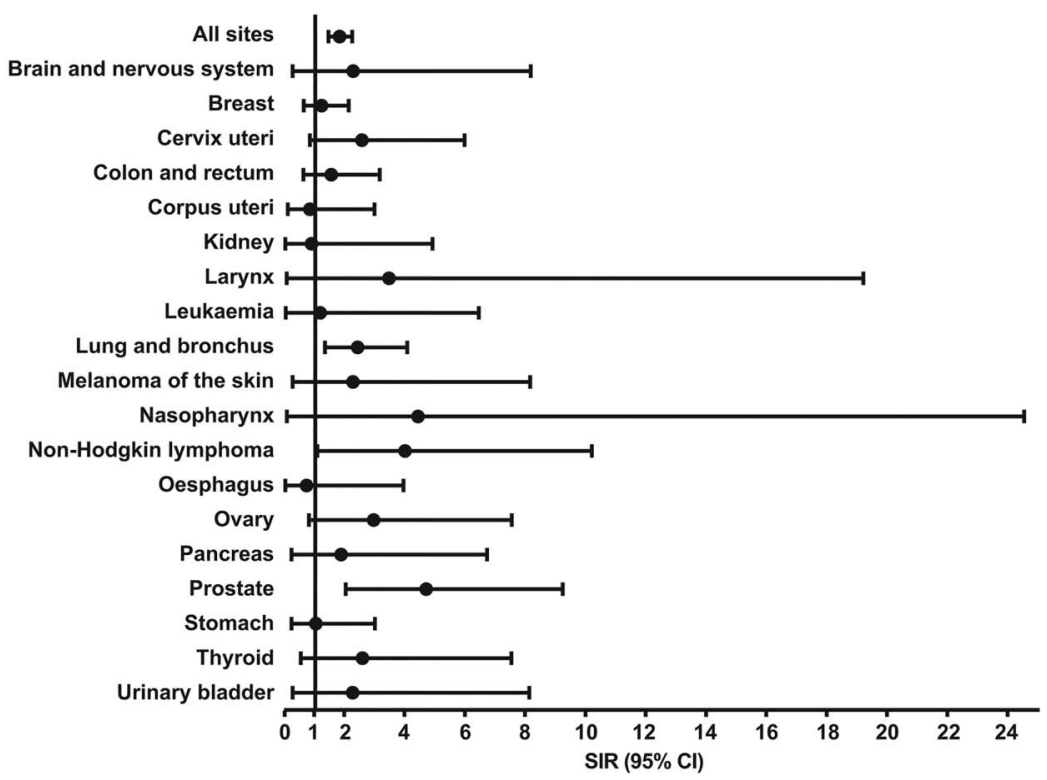

Figure 2 SIRs for malignancy for (A) US patients and (B) non-US patients (tocilizumab all-exposure population). N Obs, number observed; SIR, standardised incidence ratio. 
increased rates of certain malignancies, including non-Hodgkin lymphoma, Hodgkin lymphoma and lung cancer, in patients with RA compared with the general population. ${ }^{2}$

\section{DISCUSSION}

In long-term clinical trials in patients with RA, malignancy incidence is of particular interest because of the theoretical risk for malignancy with immunosuppression, the risk for specific malignancies in RA and the specific effects of medications and disease control, including a potentially protective effect. Tocilizumab has not been specifically studied with regard to prevention, nor has it been shown to prevent malignancy; however, increased circulating IL-6 levels may increase tumourigenesis by affecting pathways known to play a role in the development of certain malignancies. The IL-6/JAK/STAT signalling pathway regulates a number of apoptotic regulatory genes (BcL-XL, MCL-1, XIAP, c-myc, Fas). It also binds to p53, inhibiting the regulation of apoptosis. In addition, IL-6 activates Ras, MAPK, COX-2, Wnt and PI3K/AKT pathways, which contribute to the protumourigenic and antiapoptotic functions of IL-6. Data from tumour models suggest that the IL-6/JAK/STAT signalling pathway has potential roles in transformation, growth or proliferation of ovarian, lung, bladder, breast, colon and prostate cancers. ${ }^{26}$

Malignancy rates observed in patients with RA have remained stable over time, with long-term tocilizumab exposure in clinical trials. In the pooled, placebocontrolled population, the overall malignancy rate in tocilizumab-treated patients was comparable with the rate in placebo+MTX/DMARD-treated patients. No evidence for differences in the patterns or types of malignancy was reported between the two groups. In the tocilizumab all-exposure population, the adjudicated malignancy rates, both including and excluding NMSC, were numerically higher for aTNF-IR patients than for DMARD-IR patients. This may be related to increased disease duration and severity in aTNF-IR patients. A study using registry data identified an increased risk for cancer overall in patients with RA treated with aTNF compared with the general population but not compared with aTNF-naive patients. ${ }^{40}$ Patterns for sitespecific malignancies observed in aTNF-IR patients in our study were consistent with those observed in registries. ${ }^{5}{ }^{40-42}$

NMSC was the most commonly reported malignancy in the tocilizumab all-exposure population; 68 events were reported with an incidence rate of $0.4 / 100 \mathrm{PY}$ (95\% CI 0.33 to 0.54 ). This is no greater than the NMSC rate $(0.6 / 100 \mathrm{PY})$ reported in a meta-analysis of 74 trials in patients with RA treated with aTNF ${ }^{16}$ and no greater than that reported with aTNF use in a US epidemiological study (1.9/100 PY). ${ }^{18}$ Analysis of registry data has demonstrated that the rate of NMSC in aTNF-treated patients was higher than in aTNF-naive patients. ${ }^{17}$
In these global studies, the overall malignancy rate observed in the tocilizumab all-exposure population was higher than that in the general population but was consistent with that expected in the RA population and in the geographic regions studied. The numbers of cases of lung and bronchus cancer in the tocilizumab all-exposure population were higher than in the general US and non-US populations, and the numbers of cases of prostate cancer and non-Hodgkin lymphoma were higher than in the non-US general population but not higher than expected in patients with RA. An increased risk for lung cancer has been reported in epidemiological studies in patients with RA (table 2). In a meta-analysis that included 23 observational studies in patients with RA that reported SIRs for lung cancer, the overall SIR, calculated by a random-effects model, was 1.64 (95\% CI 1.51 to 1.79$){ }^{6}$ A cluster of study-specific SIRs indicated a 1.4-3.9-fold increase in the risk for lung cancer in patients with RA compared with the general population. ${ }^{6}$ In the current analysis, $83 \%$ of lung cancers occurred in patients who were current or former smokers. In the previously mentioned meta-analysis, ${ }^{6}$ based on an analysis of 22 observational studies that reported relative risk for lymphoma, the sitespecific tumour posing the highest risk for patients with RA compared with the general population was lymphoma. The overall risk for lymphoma in patients with RA was estimated to be more than twice that in the general population (SIR 2.46; 95\% CI 2.05 to 2.96 ). ${ }^{6}$ In the current analysis, the slight increase in non-Hodgkin lymphoma in tocilizumab patients was limited to the non-US population and was not unexpected given the increased risk for lymphoma in RA. An increased risk for lymphoma and lung cancer compared with the general population has also been reported in a pooled analysis of 5671 patients with RA treated with the oral Janus kinase inhibitor tofacitinib in clinical trials and long-term extensions; ${ }^{46}$ the SIR for tofacitinib-treated patients was 2.64 (95\% CI 1.27 to 4.86 ) for lymphoma and 2.19 (95\% CI 1.39 to 3.29) for lung cancer.

The increased incidence of prostate cancer observed only in non-US patients in the tocilizumab all-exposure population may be a result of differences in screening between the USA and other countries. In the USA, rates of prostate cancer rose rapidly after the high uptake of prostate-specific antigen (PSA) testing in the 1990s and then declined because of the reduced pool of prevalent cases. In contrast, incidence and mortality rates continue to rise slowly in countries with low uptake of PSA testing, including those in central and Eastern Europe, which potentially have a high prevalence of undiagnosed prostate cancer. ${ }^{47}$ This difference may explain the high number of prostate cancer cases reported in non-US patients enrolled in tocilizumab trials. The overall risk for malignancy in patients treated with tocilizumab (based on SIR analysis) was consistent with epidemiological studies of patients with RA treated with aTNF. $^{11748}$ 
Table 2 SIRs for overall and lung cancers reported in the literature in epidemiological studies of patients with RA

\begin{tabular}{|c|c|c|c|}
\hline & Cohort information & SIR & $95 \% \mathrm{Cl}$ \\
\hline \multicolumn{4}{|l|}{ All cancers } \\
\hline Thomas (females) ${ }^{43}$ & DMARD & 0.97 & 0.92 to 1.02 \\
\hline Thomas (males) ${ }^{43}$ & DMARD & 1.10 & 1.02 to 1.18 \\
\hline Ekstrom $^{44}$ & NS & 1.07 & 1.05 to 1.09 \\
\hline Wolfe $^{1}$ & Non-biological and/or biological DMARDs & 1.0 & 1.0 to 1.1 \\
\hline Abásolo ${ }^{45}$ & DMARDS, corticosteroids & 1.2 & 0.8 to 1.8 \\
\hline Hemminki $^{8}$ & NS & 1.23 & 1.19 to 1.27 \\
\hline Simon $^{6}$ & Meta-analysis* & 1.09 & 10.6 to 1.13 \\
\hline \multicolumn{4}{|l|}{ Lung cancer } \\
\hline Thomas (females) ${ }^{43}$ & DMARDs & 1.44 & 1.27 to 1.62 \\
\hline Thomas (males) ${ }^{43}$ & DMARDs & 1.32 & 1.15 to 1.51 \\
\hline \multirow[t]{2}{*}{ Askling $^{3}$} & NS & 1.48 & 1.33 to 1.65 \\
\hline & aTNF & 1.8 & 0.9 to 3.3 \\
\hline Setoguchi $^{7}$ & Non-biological and/or biological DMARDs & 1.80 & 1.52 to 2.05 \\
\hline Wolfe $^{1}$ & Non-biological and/or biological DMARDs & 1.2 & 1.0 to 1.4 \\
\hline Abásolo 45 & DMARDS, corticosteroids & 3.5 & 1.4 to 7.1 \\
\hline Hemminki $^{8}$ & NS & 1.73 & 1.57 to 1.89 \\
\hline Simon ${ }^{6}$ & Meta-analysis* & 1.64 & 1.51 to 1.79 \\
\hline
\end{tabular}

*Meta analysis included data from epidemiological studies listed above.

aTNF, antitumour necrosis factor; DMARD, disease-modifying antirheumatic drug; NS; not specified; RA, rheumatoid arthritis; SIR, standardised incidence ratio.

Two recently published integrated analyses of the RA clinical development programmes of tofacitinib $(\mathrm{n}=5671)$ and the aTNF certolizumab $(\mathrm{n}=4049)$ reported no increased risk for overall malignancy with either agent compared with that in the general population. ${ }^{49}$ The SIR for all malignancies, excluding NMSC, in the pooled analysis of tofacitinib clinical trial data was 1.17 (95\% CI 0.96 to 1.41 ) using SEER. ${ }^{46}$ The SIR for all malignancies, excluding NMSC, in a pooled analysis of certolizumab clinical trial data was 1.27 (95\% CI 0.99 to 1.61) using GLOBOCAN and 1.06 (95\% CI 0.82 to 1.33 ) using SEER. ${ }^{49}$ In the current analysis, the SIR for all malignancies, excluding NMSC, with tocilizumab (US and non-US combined) was 1.17 (95\% CI 0.98 to 13.9) using SEER and 1.80 (95\% CI 1.51 to 2.13) using GLOBOCAN (see online supplementary table S2), which is consistent with the SIRs for all malignancies in the certolizumab and tofacitinib studies.

Data available to date for patients with RA treated with subcutaneous tocilizumab are consistent with those for patients treated with intravenous tocilizumab. Based on 26 events, the rate of malignancies or unspecified tumours in the pooled, subcutaneous, all-exposure population (1465 patients; 2302.08 PY) was 1.13/100 PY (95\% CI 0.74 to 1.65 ) (data on file). There was no evidence of an increase in the rate of malignancies over time, and review of the events did not identify any clear pattern or type of events (data not shown).

This analysis does have limitations. Malignancies not collected in the SEER or GLOBOCAN databases (eg, NMSC, the most commonly reported malignancy) were not included in the SIR analysis, which compared the risk for malignancies in tocilizumab-treated patients and in the general population. In the current analysis, SIRs for specific types of malignancies were based on small numbers of cases. SIR estimates for malignancies with small numbers of observed cases could be unstable, and these data should be interpreted with that in mind. This analysis represents pooled long-term clinical trial data and is the most comprehensive analysis of malignancies with tocilizumab available to date. The relatively short placebo-controlled periods of the clinical trials, which are typical of RA clinical trial design, limited the availability of a relevant control group for the longer term data. The analysis population was limited to patients who participated in randomised placebo-controlled trials and long-term extension studies and, as such, represents a homogeneous patient cohort. Therefore, longer term and larger, real-world data sets may be needed for better understanding of the malignancy risk. Another limitation is that the medical adjudication of malignancies was not blinded to treatment received.

In conclusion, long-term data available to date for tocilizumab-treated patients in the clinical trial setting do not indicate an increased risk for overall or sitespecific malignancies above the risk expected in RA. Continued monitoring will inform on the longer term risk for malignancy with tocilizumab treatment in RA.

Acknowledgements The authors thank Sara Duggan, PhD, Maribeth Bogush, $\mathrm{PhD}$, and Meryl Mandle of ApotheCom, who provided writing services on behalf of $F$ Hoffmann-La Roche Ltd.

Funding Funding for manuscript preparation was provided by F Hoffmann-La Roche Ltd.

Competing interests AR-R has received grants and ad board/lecture fees from Roche, Pfizer and Chugai and ad board/lecture fees from Merck Sharp and Dohme, BMS and AbbVie. AS has received speaking and consulting fees from Genentech. LB, AK, BP-B, PN and JP are employees of

Roche-Genentech. RFvV has received grants from Roche, AbbVie, Amgen, 
BMS, GSK, Pfizer, Roche, UCB, Biotest, Crescendo, Janssen, Lilly, Merck Sharp and Dohme, UCB and Vertex.

Provenance and peer review Not commissioned; externally peer reviewed.

Data sharing statement No additional data are available.

Open Access This is an Open Access article distributed in accordance with the Creative Commons Attribution Non Commercial (CC BY-NC 4.0) license, which permits others to distribute, remix, adapt, build upon this work noncommercially, and license their derivative works on different terms, provided the original work is properly cited and the use is non-commercial. See: http:// creativecommons.org/licenses/by-nc/4.0/

\section{REFERENCES}

1. Wolfe F, Michaud K. Biologic treatment of rheumatoid arthritis and the risk of malignancy: analyses from a large US observational study. Arthritis Rheum 2007;56:2886-95.

2. Smitten AL, Simon TA, Hochberg MC, et al. A meta-analysis of the incidence of malignancy in adult patients with rheumatoid arthritis. Arthritis Res Ther 2008;10:R45.

3. Askling J, Fored CM, Brandt L, et al. Risks of solid cancers in patients with rheumatoid arthritis and after treatment with tumour necrosis factor antagonists. Ann Rheum Dis 2005;64:1421-6.

4. Saliba L, Moulis G, Aboutaam M, et al. The risk of cancer with tumor necrosis factor inhibitors in patients concomitantly exposed to non-biological immunosuppressants differs according to the indication [abstract]. Arthritis Rheumatol 2014;66:S373.

5. Raaschou P, Simard JF, Asker Hagelberg C, et al. Rheumatoid arthritis, anti-tumour necrosis factor treatment, and risk of squamous cell and basal cell skin cancer: cohort study based on nationwide prospectively recorded data from Sweden. BMJ 2016;352:i262.

6. Simon TA, Thompson A, Gandhi KK, et al. Incidence of malignancy in adult patients with rheumatoid arthritis: a meta-analysis. Arthritis Res Ther 2015;17:212.

7. Setoguchi S, Solomon DH, Weinblatt ME, et al. Tumor necrosis factor alpha antagonist use and cancer in patients with rheumatoid arthritis. Arthritis Rheum 2006;54:2757-64.

8. Hemminki K, Li X, Sundquist K, et al. Cancer risk in hospitalized rheumatoid arthritis patients. Rheumatology (Oxford) 2008;47:698-701.

9. Wolfe F, Michaud K. The effect of methotrexate and anti-tumor necrosis factor therapy on the risk of lymphoma in rheumatoid arthritis in 19,562 patients during 89,710 person-years of observation. Arthritis Rheum 2007;56:1433-9.

10. Askling J, Fored CM, Baecklund E, et al. Haematopoietic malignancies in rheumatoid arthritis: lymphoma risk and characteristics after exposure to tumour necrosis factor antagonists. Ann Rheum Dis 2005;64:1414-20.

11. Jones M, Symmons D, Finn J, et al. Does exposure to immunosuppressive therapy increase the 10 year malignancy and mortality risks in rheumatoid arthritis? A matched cohort study. $\mathrm{Br} J$ Rheumatol 1996;35:738-45.

12. Bernatsky S, Clarke AE, Suissa S. Hematologic malignant neoplasms after drug exposure in rheumatoid arthritis. Arch Intern Med 2008;168:378-81.

13. Georgescu L, Quinn GC, Schwartzman S, et al. Lymphoma in patients with rheumatoid arthritis: association with the disease state or methotrexate treatment. Semin Arthritis Rheum 1997;26:794-804.

14. Baecklund $\mathrm{E}$, lliadou $\mathrm{A}$, Askling $\mathrm{J}$, et al. Association of chronic inflammation, not its treatment, with increased lymphoma risk in rheumatoid arthritis. Arthritis Rheum 2006;54:692-701.

15. Bongartz T, Sutton AJ, Sweeting MJ, et al. Anti-TNF antibody therapy in rheumatoid arthritis and the risk of serious infections and malignancies: systematic review and meta-analysis of rare harmful effects in randomized controlled trials. JAMA 2006;295:2275-85.

16. Askling J, Fahrbach $\mathrm{K}$, Nordstrom $\mathrm{B}$, et al. Cancer risk with tumor necrosis factor alpha (TNF) inhibitors: meta-analysis of randomized controlled trials of adalimumab, etanercept, and infliximab using patient level data. Pharmacoepidemiol Drug Saf 2011;20:119-30.

17. Mariette X, Matucci-Cerinic M, Pavelka K, et al. Malignancies associated with tumour necrosis factor inhibitors in registries and prospective observational studies: a systematic review and meta-analysis. Ann Rheum Dis 2011;70:1895-904.

18. Amari W, Zeringue AL, McDonald JR, et al. Risk of non-melanoma skin cancer in a national cohort of veterans with rheumatoid arthritis. Rheumatology (Oxford) 2011;50:1431-9.

19. Strangfeld A, Hierse F, Rau R, et al. Risk of incident or recurrent malignancies among patients with rheumatoid arthritis exposed to biologic therapy in the German biologics register RABBIT. Arthritis Res Ther 2010;12:R5.

20. Lopez-Olivo MA, Tayar JH, Martinez-Lopez JA, et al. Risk of malignancies in patients with rheumatoid arthritis treated with biologic therapy: a meta-analysis. JAMA 2012;308:898-908.

21. Thompson AE, Rieder SW, Pope JE. Tumor necrosis factor therapy and the risk of serious infection and malignancy in patients with early rheumatoid arthritis: a meta-analysis of randomized controlled trials. Arthritis Rheum 2011;63:1479-85.

22. Moulis G, Sommet A, Béné J, et al. Cancer risk of anti-TNF- $\alpha$ at recommended doses in adult rheumatoid arthritis: a meta-analysis with intention to treat and per protocol analyses. PLOS ONE 2012;7: e48991.

23. LE Blay P, Mouterde G, Barnetche T, et al. Short-term risk of total malignancy and nonmelanoma skin cancers with certolizumab and golimumab in patients with rheumatoid arthritis: metaanalysis of randomized controlled trials. J Rheumatol 2012;39:712-15.

24. Llorca J, Lopez-Diaz MJ, Gonzalez-Juanatey C, et al. Persistent chronic inflammation contributes to the development of cancer in patients with rheumatoid arthritis from a defined population of northwestern Spain. Semin Arthritis Rheum 2007;37:31-8.

25. Assier E, Boissier MC, Dayer JM. Interleukin-6: from identification of the cytokine to development of targeted treatments. Joint Bone Spine 2010;77:532-6.

26. Guo Y, Xu F, Lu T, et al. Interleukin-6 signaling pathway in targeted therapy for cancer. Cancer Treat Rev 2012;38:904-10.

27. Suematsu S, Matsusaka T, Matsuda T, et al. Generation of plasmacytomas with the chromosomal translocation $\mathrm{t}(12 ; 15)$ in interleukin 6 transgenic mice. Proc Natl Acad Sci USA 1992;89:232-5.

28. Kawano M, Hirano T, Matsuda T, et al. Autocrine generation and requirement of BSF-2/IL-6 for human multiple myelomas. Nature 1988;332:83-5.

29. Miki S, Iwano M, Miki Y, et al. Interleukin-6 (IL-6) functions as an in vitro autocrine growth factor in renal cell carcinomas. FEBS Lett 1989;250:607-10

30. Mihara M, Kasutani K, Okazaki M, et al. Tocilizumab inhibits signa transduction mediated by both mIL-6R and sIL-6R, but not by the receptors of other members of IL-6 cytokine family. Int Immunopharmacol 2005;5:1731-40.

31. Nishimoto $\mathrm{N}$, Terao $\mathrm{K}$, Mima $\mathrm{T}$, et al. Mechanisms and pathologic significances in increase in serum interleukin-6 (IL-6) and soluble IL-6 receptor after administration of an anti-IL-6 receptor antibody, tocilizumab, in patients with rheumatoid arthritis and Castleman disease. Blood 2008;112:3959-64

32. Smolen JS, Beaulieu A, Rubbert-Roth A, et al. Effect of interleukin-6 receptor inhibition with tocilizumab in patients with rheumatoid arthritis (OPTION study): a double-blind, placebo-controlled, randomised trial. Lancet 2008:371:987-97.

33. Genovese MC, McKay JD, Nasonov EL, et al. Interleukin-6 receptor inhibition with tocilizumab reduces disease activity in rheumatoid arthritis with inadequate response to disease-modifying antirheumatic drugs: the tocilizumab in combination with traditional disease-modifying antirheumatic drug therapy study. Arthritis Rheum 2008:58:2968-80.

34. Emery P, Keystone E, Tony HP, et al. IL-6 receptor inhibition with tocilizumab improves treatment outcomes in patients with rheumatoid arthritis refractory to anti-tumour necrosis facto biologicals: results from a 24-week multicentre randomised placebo-controlled trial. Ann Rheum Dis 2008:67:1516-23.

35. Jones G, Sebba A, Gu J, et al. Comparison of tocilizumab monotherapy versus methotrexate monotherapy in patients with moderate to severe rheumatoid arthritis: the AMBITION study. Ann Rheum Dis 2010;69:88-96.

36. Kremer JM, Blanco R, Brzosko M, et al. Tocilizumab inhibits structural joint damage in rheumatoid arthritis patients with inadequate responses to methotrexate: results from the double-blind treatment phase of a randomized placebo-controlled trial of tocilizumab safety and prevention of structural joint damage at one year. Arthritis Rheum 2011;63:609-21.

37. Gabay C, Emery P, van Vollenhoven R, et al. Tocilizumab monotherapy versus adalimumab monotherapy for treatment of rheumatoid arthritis (ADACTA): a randomised, double-blind, controlled phase 4 trial. Lancet 2013;381:1541-50.

38. Schiff MH, Kremer JM, Jahreis A, et al. Integrated safety in tocilizumab clinical trials. Arthritis Res Ther 2011;13:R141.

39. Ferlay J, Soerjomataram I, Ervik M, et al. GLOBOCAN 2012 v1.0, Cancer Incidence and Mortality Worldwide: IARC CancerBase No. 11. Lyon, France: International Agency for Research on Cancer, 2013. http://globocan.iarc.fr (accessed 29 Feb 2016). 
40. Dreyer L, Mellemkjær L, Andersen AR, et al. Incidences of overall and site specific cancers in TNFalpha inhibitor treated patients with rheumatoid arthritis and other arthritides-a follow-up study from the DANBIO Registry. Ann Rheum Dis 2013;72:79-82.

41. Askling J, Baecklund E, Granath F, et al. Anti-tumour necrosis factor therapy in rheumatoid arthritis and risk of malignant lymphomas: relative risks and time trends in the Swedish Biologics Register. Ann Rheum Dis 2009;68:648-53.

42. Raaschou P, Simard JF, Holmqvist M, et al. Rheumatoid arthritis, anti-tumour necrosis factor therapy, and risk of malignant melanoma: nationwide population based prospective cohort study from Sweden. BMJ 2013;346:f1939.

43. Thomas E, Brewster DH, Black RJ, et al. Risk of malignancy among patients with rheumatic conditions. Int J Cancer 2000;88:497-502.

44. Ekström K, Hjalgrim $\mathrm{H}$, Brandt $\mathrm{L}$, et al. Risk of malignant lymphomas in patients with rheumatoid arthritis and in their first-degree relatives. Arthritis Rheum 2003;48:963-70.
45. Abásolo L, Júdez E, Descalzo MA, et al., EMECAR Study Group. Cancer in rheumatoid arthritis: occurrence, mortality, and associated factors in a South European population. Semin Arthritis Rheum 2008:37:388-97.

46. Curtis JR, Lee EB, Kaplan IV, et al. Tofacitinib, an oral Janus kinase inhibitor: analysis of malignancies across the rheumatoid arthritis clinical development programme. Ann Rheum Dis 2016;75:831-41.

47. Jemal A, Bray F, Center MM, et al. Global cancer statistics, 2011 CA Cancer J Clin 2011;61:69-90.

48. Solomon DH, Mercer E, Kavanaugh A. Observational studies on the risk of cancer associated with tumor necrosis factor inhibitors in rheumatoid arthritis: a review of their methodologies and results. Arthritis Rheum 2012;64:21-32.

49. Bykerk VP, Cush J, Winthrop K, et al. Update on the safety profile of certolizumab pegol in rheumatoid arthritis: an integrated analysis from clinical trials. Ann Rheum Dis 2015;74:96-103. 